\title{
PEMASARAN BUAH STROBERI DARI KELURAHAN RURUKAN DAN RURUKAN SATU KECAMATAN TOMOHON TIMUR, KOTA TOMOHON
}

\author{
Trisari B. Dj. Kodobik \\ Agnes E. Loho \\ Joachim N. K. Dumais
}

\begin{abstract}
ABSRACT
This study aims to find out the marketing channels of strawberries ranging from farmers in the Village Rurukan and Rurukan one to the supermarket. The research was conducted in Kelurahan Rurukan and Rurukan Satu East Tomohon Subdistrict Tomohon City for three months from May 2016 until July 2016. The data obtained are primary and secondary data. Primary data is data sourced from direct interviews with related parties, among others strawberry farmers who became the subject of research. Secondary data is data obtained by the researcher who sourced from documents from related agencies, such as: Rurukan urban village office and Rurukan Satu East Tomohon subdistrict Tomohon City, internet and library sources or literature book data is analyzed by using marketing margin, farmer's share and profit margin. Based on the results of marketing channel research as much as two channels of marketing channel I ranging from farmers to final consumers, marketing channels II farmers to the Supermarket divided into two places namely Cool Tomohon and Freshmart Bahu. The result of marketing Margin of strawberry fruit on channel I is Rp. $0(0 \%)$. For marketing margin value II is Rp. 6500 (30, 23\%) (Cool) and Rp. 13,000 (46, 42\%) (Freshmart). This shows that the largest margin of marketing value occurs in the marketing channel II in the supermarket Freshmart. The largest profit margin in the strawberry fruit sequence that occurs in marketing channel I between farmers to consumers with profit margin of Rp. 13,250 (98.14\%). *jnkd*
\end{abstract}

Keywords: Marketing, Strawberry Fruit, East Tomohon District, Timur Subdistrict, Tomohon City

\begin{abstract}
ABSTRAK
Penelitian ini bertujuan untuk mengetahui saluran pemasaran buah stroberi mulai dari petani yang ada di Kelurahan Rurukan dan Rurukan Satu sampai kepada supermarket. Penelitian dilakukan di Kelurahan Rurukandan Rurukan satu Kecamata Tomohon Timur Kota Tomohon selama tiga bulan dari bulan Mei 2016 sampai Juli 2016. Data yang diperoleh adalah data primer dan sekunder. Data primer yaitu data yang bersumber dari wawancara langsung dengan pihak-pihak yang terkait antara lain petani stroberi yang menjadi subjek dalam penelitian. Data sekunder yaitu data yang diperoleh oleh peneliti yang bersumber dari dokumen dari instansi terkait, seperti Kantor Kelurahan Rurukan dan Rurukan satu Kecamatan Tomohon Timur Kota Tomohon, internet dan sumber pustaka atau buku literature data di anilisis dengan menggunakan analisis margin pemasaran, farmer's share dan profit margin. Berdasarkan hasil penelitian saluran pemasaran sebanyak dua saluran yaitu Saluran pemasaran I mulai dari petani ke konsumen akhir, saluran pemasaran II petani ke Supermarket terbagi dua tempat yaitu Cool Tomohon dan Freshmart Bahu. Hasil dari analisis Margin pemasaran buah stroberi, nilai margin pemasaran pada saluran I adalah Rp. 0 (0\%). Untuk nilai margin pemasaran II adalahRp. 6500 (30, 23\%) (Cool) dan Rp. 13.000 (46,42\%) (Freshmart). Ini menunjukan bahwa nilai margin pemasaran terbesar terjadi pada saluran pemasaran II yaitu di supermarket Freshmart. Profit margin terbesar dalam pemasaraan buah stroberi yaitu terjadi pada saluran pemasaran I antara petani ke konsumen dengan profit margin sebesar Rp. $13.250(98,14 \%)$.
\end{abstract}

Kata kunci: Pemasaran, Buah Stroberi, Kecamatan Tomohon Timur, Kota Tomohon 


\section{PENDAHULUAN}

\section{Latar Belakang}

Tanaman stroberi merupakan tanaman buah yang ditemukan pertama kali di Chili, Amerika. Salah satu spesies tanaman stroberi yaitu Fragari choiloensis $L$ lebih menyebar luas di bangdingkan spesies lainnya. Jenis stroberi ini pula yang pertama kali masuk ke Indonesia. Stroberi yang kita temukan di pasar swalayan ialah hibrida yang dihasilkan dari persilangan Fragaria virgiana $L$ var Duchesneasal Amerika utara dengan Fragaria ChiloensisL var Duchesne asal Chili (Darwis, 2007). Seiring perkembangan ilmu dan teknologi pertanian yang semakin maju, kini stroberi mendapat perhatian pengembangannya didaerah beriklim tropis. Di Indonesia, walaupun stroberi bukan merupakan tanaman asli Indonesia, namun pengembangan komoditas ini yang berpola agribisnis dan agroindustri dapat dikategorikan sebagai salah satu sumber pendapatan dalam sektor pertanian. Stroberi ternyata dapat tumbuh dan berproduksi dengan baik dalam kondisi iklim seperti di Indonesia (Budiman dan Saraswati, 2008). Hal ini terlihat dari beberapa perkebunan stroberi di Indonesia yaitu di Lembang, Ciwidey (Bandung), Cipanas (Cianjur), Batu (Malang), Tabanan, Bedugul (Bali), Karangmulya (Garut), dan Sawangan (Magelang) yang dikenal sebagai sentra stoberi di Indonesia. Banyaknya industri pengolahan yang memanfaatkan stroberi sebagai bahan baku serta pasar yang membutuhkan stroberi untuk konsumsi segar juga turut mempengaruhi potensi untuk pengembangan budidaya Stroberi. Perkembangan budidaya stroberi di Indonesia memberikan titik terang. Tingkat pertumbuhan petani stroberi terus meningkat dari tahun ke tahun. Hal ini dapat di lihat di Daerah Bandung Selatan, tepatnya di Ciwidey yang luas lahannya sekitar 15 Ha digunakan untuk budidaya stroberi, di Lambang luas lahannya sekitar $7 \mathrm{Ha}$, dan di Garut luas lahannya sekitar $5 \mathrm{Ha}$ dengan populasi tanaman per hektar sekitar 50.000 Ribu tanaman. Sayangnya, petani masih menggunakan pola tanam yang sifatnya konvensional. Kelemahan atas pengolahan lahan yang tidak terpadu bisa menimbulkan kerentanan tanaman terhadap hama dan penyakit serta dapat mengurangi kuantitas dan kualitas produksi. Permintaan stroberi di Ciwidey, Kabupaten Bandung, selama tahun 2005 mencapai 700$1000 \mathrm{~kg}$ per hari, namun petani hanya mampu memenuhi namun petani hanya mampu memenuhi kebutuhan stroberi sebanyak 700 $\mathrm{kg} /$ hari (Radius, 2008). Usaha budidaya stroberi ini menjanjikan untuk dikembangkan dalam skala nasional, produksi stroberi di Indonesia meningkat yang semula 41.035 ton pada tahun 2011 menjadi 169. 796 ton pada tahun 2012 (Deptan, 2015).

Tomohon adalah salah satu kota di Provinsi Sulawesi Utara, Kota Tomohon, berjarak $25 \mathrm{~km}$ arah selatan dari Kota Manado, Ibu Kota Provinsi Sulawesi Utara. Kota Tomohon berbatasan langsung dengan Kabupaten Minahasa, luas Kota Tomohon adalah 147,21 Km². Kawasan Rurukan sebagai daerah daratan tinggi yang merupakan daerah potensial untuk mengembangkan usaha stroberi, yang bukan hanya dapat menjadi topangan hidup petani tetapi juga dapat membawah keuntungan bagi petani pengembang tanaman stroberi sehingga diharapkan dapat meningkatkan penghasilan bagi petani stroberi. Usaha tani stroberi di Kelurahan Rurukan dan Rurukan Satu mayoritas dilakukan petani secara pribadi atau mandiri dengan jumlah petani yang awalnya sebanyak dua puluh orang petani sekarang hanya ada tersisa lima orang petani saja yang masih mengembangkan buah stroberi di Kelurahan Rurukan dan Rurukan Satu. Beberapa masalah yang terjadi dalam usaha mengembangkan budidaya stroberi pada petani yaitu modal, petani tidak mampu memenuhi permintaan pada supermarket, pemasaraan hasil panen, dan pembibitan. Hasil produksi buah stroberi dipasarkan langsung ke konsumen akhir dan pada Supermarket Cool yang berada di Tomohon, Supermarket Freshmart yang terletak di Kota Manado tanpa bantuan pedagang perantara. Ada juga konsumen yang berasal dari luar Daerah Kelurahan Rurukan seperti dari Gorontalo, Airmandidi dan Manado yang datang berwisata ke puncak Rurukan dan langsung ke kebun stroberi untuk membeli buah stroberi. Oleh karena itu, perlu dilakukan suatu kajian 
dengan tujuan untuk mengetahui pemasaran buah stroberi dari Kelurahan Rurukan dan Rurukan Satu Kecamatan Tomohon Timur dengan menelusuri saluran pemasaran yang berlaku.

\section{Rumusan Masalah}

Berdasarkan latar belakang yang telah diuraikan, maka yang menjadi rumusan masalah dalam penelitian ini adalah bagaimana Pemasaran buah Stroberi dari Kelurahan Rurukan dan Rurukan Satu Kecamatan Tomohon Timur Kota Tomohon?

\section{Tujuan Penelitian}

Tujuan penelitian ini yaitu mengetahui pemasaran buah stroberi dari Kelurahan Rurukan dan Rurukan Satu yang di mulai dari petani stroberi sampai pada konsumen akhir dan supermarket, serta menganalisis perbedaan margin, farmer's share, dan profit margin yang terjadi pada masing-masing saluran pemasaran.

\section{Manfaat Penelitian}

1. Bagi petani, mampu memberikan informasi bagi petani stroberi dalam rangka meningkatkan produktifitas dan memudahkan kegiatan pemasaran hasil panen.

2. Bagi lembaga pemasaran, penelitian ini dapat menambah referensi dalam mengambil suatu keputusan untuk memenuhi kebutuhan dan keinginan pasar, dengan mempertahankan dan meningkatkan kesejatraan konsumen

3. Bagi pihak lain, penelitian ini dapat menjadi bahan pertimbangan dalam melakukan penelitian yang sejenis.

\section{METODOLOGI PENELITIAN}

\section{Waktu dan Tempat Penelitian}

Penelitian ini dilaksanakan selama 3 (tiga) bulan yakni mulai dari bulan Mei sampai bulan Juli tahun 2016 yang dimulai dari persiapan, pengolahan data sampai pembuatan laporan. Lokasi penelitian ini dilaksanakan di Kelurahan Rurukan dan Rurukan Satu Kecamatan Tomohon Timur Kota Tomohon.

\section{Metode Pengumpulan Data}

Metode pengambilan data yang digunakan dalam penelitian ini adalah data primer dan data sekunder. Data primer diperoleh dengan menggunakan teknik wawancara langsung kepada petani stroberi yang hanya berjumlah sebanyak 5 (lima) petani responden dan menggunakan daftar pertanyaan (quesioner) sebagai alat bantu dalam pengumpulan data. Sedangkan data sekunder diperoleh dari instansiinstansi yang terkait dalam penelitian ini yakni Kantor Kelurahan Rurukan dan Kelurahan Rurukan Satu Kecamatan Tomohon Timur Kota Tomohon.

\section{Metode Pengambilan Sampel}

Untuk mengetahui bagaimanakah Pemasaran Stroberi Dari Kelurahan Rurukan dan Rurukan Satu, maka metode yang diambil dalam penelitian ini adalah dengan cara Sampel Bola Salju (SnowBall Sampling). Pengambilan sampel dalam penelitian ini adalah seluruh petani stroberi yang ada di Kelurahan Rurukan dan Rurukan Satu yang berjumlah 5 orang 2 orang petani yang berada dikelurahan Rurukan sedangkan 3 orang petani lainnya berada dikelurahan Rurukan Satu.

\section{Konsep Pengukuran Variabel}

Variabel-variabel yang diukur dalam penelitian ini adalah sebagai berikut:

1. Karakteristik petani responden:

a. Umur yaitu usia sejak petani stroberi dilahirkan sampai saat menjadi responden dalam penelitian (tahun).

b. Tingkat pendidikan petani yaitu lamanya petani duduk dibangku sekolah formal (SD/SMP/SMA/Perguruan Tinggi)

c. Jumlah Tanggungan Keluarga petani yaitu menunjukan jumlah anggota keluarga dalam rumah tangga responden (Orang)

d. Pengalaman bertani, yaitu lamanya responden bekerja sebagai petani stoberi (tahun)

2. Sistem pemasaran produk stroberi pada petani

3. Harga Jual stroberi yang berlaku ditingkat petani ( $\mathrm{Rp} /$ kemasan)

4. Harga jual stroberi yang berlaku pada supermarket(Rp / kemasan) 
5. Biaya Pemasaran yang dikeluarkan petani dalam satu kali pengantaran dinyatakan dalam rupiah $(\mathrm{Rp})$, meliputi:

a. Biaya Pengangkutan, stroberi ditingkat produsen ( $\mathrm{Rp} /$ kemasan)

b. Biaya Pengepakan ( $\mathrm{Rp} /$ kemasan)

\section{Metode Analisis Data}

Untuk menghitung margin pemasaran atau menghitung selisih antara harga yang dibayar konsumen dengan harga yang diterima produsen dengan menggunakan rumus:

$\mathrm{M}=\mathrm{Pr}-\mathrm{Pf}$

Keterangan:

$\mathrm{M}=$ Marjin pemasaran

$\operatorname{Pr}=$ Harga di tingkat konsumen

$\mathrm{Pf}=$ Harga di tingkat petani

Farmer's share memiliki hubungan negatif dengan margin pemasaran, sehingga semakin tinggi margin pemasaran maka bagian yang akan diperoleh petani semakin rendah. Secara matematis, farmer's share dapat dirumuskan sebagai berikut:

Dimana,

$F S=\frac{P}{K} \times 100 \%$

Keterangan:

$\mathrm{FS}=$ Farmer's share

$\mathrm{P}=$ Harga di tingkat petani

$\mathrm{K}=$ Harga yang dibayarkan oleh konsumen akhir. Adapun cara lain untuk menghitung biaya marjin dan profit marjin dapat dirumuskan dalam model persamaan berikut:

$\mathrm{P}=\mathrm{M}-\mathrm{C}$

Keterangan:

$\mathrm{P}=$ Profit Margin

$\mathrm{M}=$ Margin Pemasaran

$\mathrm{C}=$ Total Biaya Pemasaran

\section{HASIL DAN PEMBAHASAN}

\section{Deskripsi Wilayah Penelitian}

Kelurahan Rurukan terletak di Kecamatan Tomohon Timur Kota Tomohon Provinsi Sulawesi Utara dan berada pada ketinggian 1100-1300 dpl dengan luas wilayah \pm 350 Ha. Kelurahan Rurukan Satu terletak di Kecamatan Tomohon Timur Kota Tomohon Provinsi Sulawesi Utara dan berada pada ketinggian 1080 dpl dengan luas wilayah 155,8 Ha. Batas wilayah kelurahan Rurukan dan Rurukan Satu dapat dilihat pada Tabel 1.

Tabel 1. Batas Wilayah Penelitian

\begin{tabular}{llc}
\hline Batas & Kelurahan & $\begin{array}{c}\text { Kelurahan } \\
\text { Rurukan Satu }\end{array}$ \\
\hline Utara & Kelurahan & Rurukan \\
Timur & Kumelembuai & Rurukan \\
Selatan & Rurukan Satu & Rurukan \\
Barat & Kabupaten & Wewelen- \\
& Minahasa & Kembuan \\
& Talete Satu dan & Tondano \\
& Paslaten Satu & \\
\hline Sumber: Kantor Kelurahan Rurukan dan Kelurahan \\
\multicolumn{3}{c}{ Rurukan Satu }
\end{tabular}

\section{Keadaaan Penduduk (Demografi)}

Penduduk merupakan salah satu modal atau aset suksesnya kegiatan pembangunan. Peranan yang dilakukan oleh penduduk akan dapat menentukan perkembangan wilayah pada suatu wilayah atau daerah. Penduduk di Kelurahan Rurukan berjumlah 1793 jiwa, dengan perincian laki-laki berjumlah 950 jiwa dan perempuan berjumlah 843 jiwa. Penduduk di Kelurahan Rurukan Satu berjumlah 1250 jiwa, dengan perincian laki-laki 626 jiwa dan perempuan 624 jiwa.

\section{Karakteristik Responden}

\section{Karakteristik Responden Stroberi}

Karakteristik responden yang menjadi narasumber dalam penelitian adalah petani stroberi yang berada di Kelurahan Rurukan dan Kelurahan Rurukan Satu yaitu sebanyak 5 orang petani responden. Dalam usaha produksi buah stroberi ini, seluruh petani responden mengungkapkan bahwa faktor harga yang baik dengan pemasaran yang mudah dan terjamin sehingga menjadi salah satu alasan bagi mereka menggeluti usaha ini, ada juga petani yang berpendapat bahwa mereka memilih mengembangkan stroberi selain karena hobi, mereka juga dapat menambah penghasilan seharihari dari menanam stroberi. Menurut salah satu responden menyatakan bahwa budidaya stroberi di kelurahan Rurukan sangat cocok dengan iklim lokasi yang mereka diami, sehingga mendukung mereka untuk membudidayakan buah stroberi. 


\section{Umur Petani Stroberi}

Umur petani sangat mempengaruhi produktivitas kerja atau peranannya dalam pengambilan keputusan dari berbagai alternatif pekerjaan yang dilakukan. Umur petani memiliki hubungan dengan kemampuan petani dalam bekerja. Jika ditinjau dari segi fisik, semakin tua umur seorang setelah melewati batas umur tertentu, maka semakin berkurang kemampuan untuk bekerja. Data responden petani umur 30-40 tahun sebanyak 1 orang petani atau $20 \%$ dari total responden. Untuk petani umur 41-54 tahun Sebanyak 3 orang petani atau $60 \%$, dan petani umur $\geq 55$ sebanyak 1 orang atau $20 \%$ dari total responden. Umur petani responden dapat dilihat pada Tabel 2.

Tabel 2. Umur Petani Stroberi di Kelurahan Rurukan Dan Rurukan Satu

\begin{tabular}{lccc}
\hline \multicolumn{4}{c}{ Rurukan Dan Rurukan Satu } \\
No & $\begin{array}{c}\text { Umur } \\
\text { (Tahun) }\end{array}$ & $\begin{array}{c}\text { Jumlah } \\
\text { (orang) }\end{array}$ & $\begin{array}{c}\text { Persentase } \\
(\%)\end{array}$ \\
\hline 1 & $30-40$ & 1 & 20 \\
2 & $41-54$ & 3 & 60 \\
3 & $\geq 55$ & 1 & 20 \\
\hline & Jumlah & 5 & 100 \\
\hline
\end{tabular}

Sumber : Data di olah dari data primer

\section{Tingkat Pendidikan Petani Stroberi}

Pendidikan ialah salah satu faktor yang menentukan produktifitas kerja, sikap serta kemampuan seseorang dalam mengambil keputusan dan bertindak. Tingkat pendidikan petani dapat dilihat pada Tabel 3 .

Tabel 3. Jumlah Petani Berdasarkan Tingkat

\begin{tabular}{lccc}
\multicolumn{3}{c}{ Pendidikan } & \\
No & $\begin{array}{c}\text { Tingkat } \\
\text { Pendidikan }\end{array}$ & $\begin{array}{c}\text { Jumlah } \\
\text { (Orang) }\end{array}$ & $\begin{array}{c}\text { Persentase } \\
(\%)\end{array}$ \\
\hline 1 & SD & 1 & 20 \\
2 & SMP & 1 & 20 \\
3 & SMA & 3 & 60 \\
\hline Jumlah & & 5 & 100 \\
\hline
\end{tabular}

Sumber : Diolah dari data primer

Tabel 3 terlihat bahwa petani dengan tingkat pendidikan SD berjumlah 1 orang atau 20 $\%$, dan untuk responden petani yang berpendidikan SMP berjumlah 1 orang atau 20 $\%$, sedangkan untuk tingkat pendidikan SMA memiliki jumlah paling banyak yaitu berjumlah 3 orang atau $60 \%$.

\section{Tanggungan Keluarga Petani Stroberi}

Jumlah anggota keluarga ialah salah satu faktor penunjang keberhasilan dalam berusaha tani. Berikut dapat dilihat jumlah tanggungan keluarga dari keseluruhan petani stroberi. Dari 5 orang petani ada 3 petani yang memiliki jumlah tanggungan keluarga sebanyak 3 orang atau 60 $\%$. Sedangkan untuk petani yang memiliki jumlah tanggungan keluarga 4-5 orang sebanyak 2 orang atau $40 \%$.

\section{Pengalaman Bertani Petani Stroberi}

Pengalaman seorang petani sangat mempengaruhi produktivitas hasil panen karena dari pengalaman dapat diukur tingkat produktifitas petani. Pengalaman usahatani yang dimiliki oleh petani stroberi sangat mempengaruhi kegiatan dan keahlihannya dalam melakukan usahatani stroberi ini serta mempelajari teknik baru. Hasil penelitian mengenai pengalaman bertani seperti terlihat pada Tabel 4.

Tabel 4. Jumlah Petani Berdasarkan Pengalaman Dalam Bertani

\begin{tabular}{llll}
\multicolumn{4}{c}{ Dalam Bertani } \\
\hline No & Tahun & Jumlah Orang & Presentase (\%) \\
\hline 1 & $\geq 5$ & 3 & 60 \\
2 & 3 & 1 & 20 \\
3 & 4 & 1 & 20 \\
\hline Jumlah & & 5 & 100 \\
\hline
\end{tabular}

Sumber : Diolah dari data primer

Tabel 4 dapat dilihat bahwa petani dengan pengalaman bertani stroberi di Desa Rurukan Dan Rurukan Satu $\geq 5$ tahun yaitu sebanyak 3 Orang responden atau $60 \%$, untuk responden petani yang pengalaman bertani 3 tahun sebanyak 1 orang responden atau $20 \%$, dan petani yang pengalaman bertani 4 tahun tahun sebanyak 1 orang atau $20 \%$.

\section{Pemasaran Produk Buah Stroberi}

Pemasaran adalah suatu telaah terhadap aliran produk secara fisik dan ekonomik yaitu dari produsen mulai pedagang perantara sampai ke konsumen. Saluran pemasaran buah stroberi di Kelurahan Rurukan dan Rurukan Satu dimulai dari petani langsung kepada konsumen sampai pada supermarket Cool Tomohon dan Freshmart Bahu. Sebelum buah stroberi dipasarkan petani 
melakukan penyortiran buah stroberi terlebih dahulu kemudian dikemas dalam bentuk yang berukuran yang lebih yaitu dengan menggunakan plastik mika, dan dalam kemasan belum diberikan label produksi pada kemasan.

Petani di Kelurahan Rurukan menjual produk stroberi secara langsung kepada konsumen sampai pada supermarket Cool Tomohon dan Freshmart Bahu tanpa melibatkan bantuan dari perantara. Ada juga konsumen dari luar daerah Rurukan seperti dari Gorontalo, Airmadidi, dan Manado datang berwisata ke Puncak Rurukan. Konsumen tersebut langsung datang ke kebun stroberi untuk membeli buah stroberi dengan cara memetik sendiri. Konsumen yang memetik langsung dikebun kemudian petani menimbang beratnya, dan biasanya petani menjual produk stroberi dengan harga Rp.13.500 per 100 gram atau 1 kemasan stroberi kepada konsumen yang datang langsung dikebun. Harga jual buah stroberi di tingkat petani pada supermarket Cool dan Freshmart adalah sebesar Rp.15.000. Harga jual di supermarket Cool sebesar Rp.21.500,- per kemasan. Harga jual stroberi di supermarket Freshmart sebesar Rp.28.000,- per kemasan. Sistem pembayaran yang terjadi antara supermarket dengan petani dilakukan dengan cara dibayar setiap dua hari sekali pengantaran stroberi. Kerja sama antara petani stroberi dengan supermarket Freshmart sudah berjalan sejak tahun 2011 sampai tahun 2016. Kerja sama dengan supermarket Cool baru berjalan mulai tahun 2014. Di akhir tahun 2015 sampai pada tahun 2016, petani di Kelurahan Rurukan dan Rurukan Satu mengalami penurunan produksi buah stroberi karena faktor iklim/cuaca panas panjang yang terjadi pada akhir tahun 2015 membuat daun dan tangkai tanaman stroberi menjadi layu, kekeringan, sehingga produksi buah stroberi menjadi sedikit karena kekurangan air membuat petani sudah tidak dapat memenuhi permintaan dari supermarket.

\section{Analisis Saluran Pemasaran Buah Stroberi}

Petani stroberi melakukan penjualan melalui tiga saluran pemasaran yaitu pada saluran satu di mulai dari petani ke konsumen akhir, saluran pemasaran dua terbagi menjadi dua tempat yaitu dari petani ke supermarket Cool Tomohon dan supermarket Freshmart Bahu. Saluran pemasaran ini dapat pada Gambar 1.

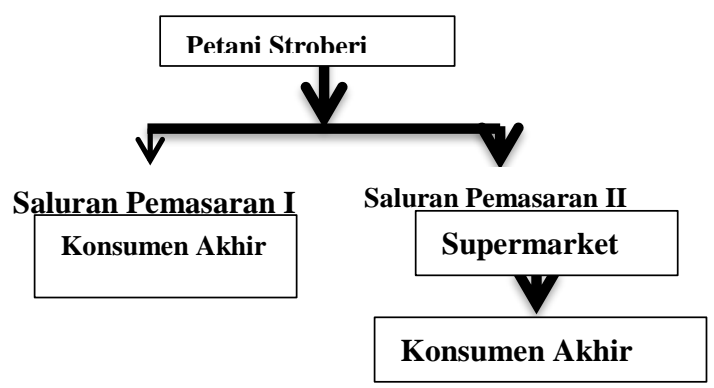

Gambar 1. Saluran Pemasaran Buah Stroberi

\section{Saluran Pemasaran I (Petani ke Konsumen Akhir)}

Saluran pemasaran I terdiri daripetani ke konsumen akhir. Saluran pemasaran ini tidak menggunakan lembaga perantara oleh karena itu saluran ini memiliki rantai pemasaran paling pendek. Seluruh petani stroberi memilih saluran pemasaran ini sebagai salah satu alternative saluran pemasaran yang mereka miliki. Petani memilih untuk menjual stroberi langsung di tempat Wisata Rurukan, Sekertariat kelompok tani Agape dan di kebun stroberi langsung namun ada konsumen yang datang langsung membeli buah stroberi di kebun yang berdekatan dengan tempat Wisata Rurukan. Harga jual stroberi yang terjadi pada saluran pemasaran I antara Rp. 13.500 - 15.000,rupiah per kemasan, tergantung pada hasil produksi buahnya.

\section{Saluran Pemasaran II (Petani ke Supermarket)}

Saluran pemasaran II terdiri dari produsen-supermarket terbagi menjadi dua tempat yaitu di supermarket Cool Tomohon dan Freshmart Bahu membeli buah stroberi yang masih segar langsung dari petani stroberi untuk dijual langsung pada konsumen akhir. Supermarket Cool dan Freshmart Bahu membeli buah stroberi mulai dari 50-100 kemasan stroberi dalam dua hari sekali pemesanan. Pada saluran pemasaran II ini, harga jual buah stroberi dari petani ke supermarketsebesar Rp. 15.000per kemasan. Harga jual stroberi berbeda-beda tergantung pada produksi buah dan jarak penjualan yang dilakukan. Dengan demikian harga jual petani kepada supermarket lebih tinggi dari harga jual 
langsung ke konsumen akhir.

\section{Harga Jual Buah Stroberi}

Harga merupakan persetujuan antara pembeli dan penjual dalam menilai suatu produk tertentu (Seomarsono, 1990). Harga stroberi yang berlaku petani stroberi di Kelurahan Rurukan dan Rurukan Satu mencapai Rp. $150.000 / \mathrm{kg}$ dalam 10 kemasan stroberi dimana dalam 1 kemasan mempunyai berat 100 Gram. Harga stroberi dari petani langsung ke konsumen akhir yaitu Rp. 13.000 - 15.000 per kemasan tergantung pada hasil produksi buah. Harga stroberi dari petani ke supermarket Cool dan Freshmart adalah Rp.15.000 /kemasan.

\section{Biaya Pemasaran Buah Stroberi}

Biaya pemasaran dalam penelitian ini diartikan sebagai biaya yang dikeluarkan oleh produsen buah stroberi dalam melakukan fungsi-fungsi pemasaran untuk upaya memasarkan buah stroberi dari produsen hingga sampai ke konsumen sesuai dengan waktu, nilai, bentuk, dan harga yang sesuai dengan keinginan konsumen. Adapun biayabiaya yang di tanggung oleh petani stroberi adalah biaya pengangkutan, dan biaya pengepakan.

\section{Biaya Pengepakan Stroberi}

Biaya pengepakan merupakan biaya yang dikeluarkan oleh produsen untuk tahap pengemasan buah stroberi yang masih segar atau baru di petik dari kebun langsung di pindahkan dalam satuan berat yang berukuran lebih kecil. Dalam proses pengemasan buah stroberi umumnya dilakukan dengan menggunakan plastik mika untuk dipasarkan. Berat rata-rata / kemasan adalah 100 gram, dalam satu kemasan terisi sekitar 6-10 buah stroberi tergantung pada besar-kecilnya ukuran buah stroberi, proses pengepakan tentunya petani harus mengeluarkan biaya-biaya yaitu dapat dilihat pada Tabel 5. Untuk membeli plastik mika, hekter dan peluru hekter petani mengeluarkan biaya sebesar Rp. 25.000,$(1.85 \%)$ untuk 100 kemasan, dan rata-rata biaya per kemasan adalah sebesar Rp. 250.-.
Rata-rata biaya pengepakan dari petani sampai kepada Cool Tomohon yaitu sebesar Rp. $25.000(1,66 \%)$. Biaya pengepakan yang dikeluarkan oleh petani kepada Freshmart Bahu juga sama seperti pada saluran pemasaran I yaitu sebesar Rp. 25.000,- (1,66 $\%$ ) untuk 100 kemasan.

\section{Biaya Pengangkutan Buah Stroberi}

Biaya pengangkutan adalah biaya yang dikeluarkan oleh petani dalam memasarkan buah stroberi yang sudah dikemas dari lokasi petani hingga sampai pada lokasi supermarket Cool dan Freshmart Bahu. Proses pengangkutan yang terjadi umumnya menggunakan sepeda motor (ojek), petani stroberi memasok buah stroberi pada supermarket Cool Tomohon dan Freshmart Bahu dalam jangka waktu satu minggu tiga kali pengangkutan, dalam satu bulan petani memasok produk stroberi kepada supermarket Cool dan Freshmart sebanyak 8-10 kali. Biaya pengangkutan yang dikeluarkan oleh petani pada masing-masing saluran pemasaran berbeda-beda, tergantung pada jarak yang akan ditempuh dengan biaya-biaya yang dikeluarkan datap dilihat pada Tabel 6. Biaya pengangkutan yang di keluarkan petani dalam satu kali pengangkutan pada supermarket Cool adalah Rp. 20,000,- (0,13\%) untuk 100 kemasan dan rata-rata biaya pengangkutan pada Cool Tomohon dalam satu kemasan sebesar Rp. 200 rupiah untuk satu kali pengangkutan. Biaya pengangkutan pada supermarket Freshmart dalam satu kali pengangkutan adalah Rp. 50,000,- untuk 100 kemasan. Rata-rata biaya pengangkutan yang di keluarkan petani per kemasan adalah Rp. 500 rupiah.

\section{Analisis Margin Pemasaran Buah Stroberi}

Analisis mengenai margin pemasaran dan farmer's share dilakukan dengan perhitungan margin pemasaran yang diperoleh oleh lembaga pemasaran berdasarkan pengurangan harga penjualan dengan harga pembelian dan biaya yang dikeluarkan. Hasil 
perhitungan terhadap biaya, keuntungan, margin pemasaran, dan sebaran margin pemasarannya dianalisis lebih lanjut untuk mengetahui besarnya margin yang diperoleh masing-masing lembaga pemasaran dan tingkat efisiensi saluran. Jalur pemasaran yang efisen terjadi apabila rasio margin total lebih tinggi dibandingkan jalur lainnya. Perolehan pendapatan dari produsen (farmer's share) yang lebih besar dibandingkan perolehan pendapat menyeluruh (market's share) menunjukan harga ditingkat konsumen akhir dapat memberi insentif bagi petani. Efisiensi pemasaran juga dapat dilihat dari kecilnya biaya pemasaran pada masing-masing lembaga pemasaran.

\section{Saluran Pemasaran Buah Stroberi Saluran Pemasaran I (Petani ke Konsumen Akhir)}

Saluran pemasaran adalah lembaga pemasaran yang melakukan proses penjualan dimulai dari produsen sampai ke konsumen akhir. Di Kelurahan Rurukan dan Rurukan Satu terdapat dua saluran pemasaran yaitu dimulai dari petani langsung ke konsumen hingga sampai pada Supermarket Cool dan Freshmart Bahu. Rincian margin dan farmer's share seperti terlihat pada Tabel 7. Produsen tidak mengeluarkan biaya pengangkutan karena hanya menjual buah stroberi di tempat wisata Rurukan, dan langsung menjualnya dikebun stroberi dengan harga per kemasan sebesar Rp. 13.500. Biaya pengemasan produsen mengeluarkan biaya per kemasan sebesar Rp. 250 (1.85\%). Margin pemasaran yaitu Rp. 0 ( $0 \%$ ). Profit margin sebesar Rp. 13.250 (98.14\%). Nilai farmer's share yang terjadi pada saluran ini sebesar 100 persen, menunjukan bahwa bagian yang diterima produsen buah stroberi yang ada di Kelurahan Rurukan dan Rurukan Satu sudah paling maksimal dan memberikan insentif penuh bagi produsen.

Saluran Pemasaran II (Petani ke Supermarket)

Saluran pemasaran antara petani dengan supermarket terbagi menjadi dua tempat yaitu pada Cool Tomohon dan Freshmart Bahu. Petani mengeluarkan biaya pengemasan buah stroberi yang dikemas dalam bentuk yang lebih kecil yaitu menggunakan plastik mikka dan hekter membutuhkan biaya-biaya seperti terlihat pada Tabel 8. Berdasarkan Tabel 8 dapat terlihat bahwa pada saluran pemasaran II, nilai margin pemasaran yang terjadi pada supermarket Cool Tomohon adalah sebesar Rp 6.500 (30,23\%) dari harga beli konsumen. Profit margin yang di peroleh sebesar Rp. 6050 (28.13\%) dari harga beli konsumen. Biaya pengepakan sebesar Rp. 250 (1,16\%). dengan biaya pengangkutan yang dikeluarkan oleh petani adalah sebesar Rp. 200,- $(0.93 \%)$ per kemasan. Farmer's Share, pada Cool Tomohon adalah 69,76 \%, harga jual pada Cool Tomohon sebesar Rp. 21.500,-. (100 \%). Sedangkan nilai margin pemasaran yang terjadi pada Freshmart Bahu sebesar Rp. $13.000(46.42 \%)$ dari harga beli konsumen. Dengan biaya pengemasan yang dikeluarkan oleh petani pada Freshmart Bahu, sama seperti biaya yang dikeluarkan pada Cool Tomohon yaitu sebesar Rp. 250 (0.89 \%). Biaya pengangkutan pada Supermarket Freshmart Bahu, petani mengeluarkan biaya sebesar Rp. $500(1.78 \%)$ per kemasan. Profit margin yang terjadi sebesar Rp. 12.250 (43.75\%). Nilai Farmer's Share, antara Petani dan Freshmart Bahu sebesar 53,57 \%. Harga jual pada Freshmart Bahu sebesar Rp. 28.000,- (100\%) /kemasan.

Dari kedua saluran pemasaran yang ada, terlihat bahwa profit margin yang di peroleh saluran pemasaran I sebesar Rp. 13.250 (98.14\%), maka profit margin yang paling banyak di dapat dari hasil penjualan langsung ke konsumen karena petani tidak mengeluarkan biaya pengangkutan. Sedangkan profit margin pada saluran pemasaran II yaitu Cool dan Freshmart sebesar Rp. 6050 (28.13\%), menunjukan bahwa profit margin terkecil terdapat pada supermarket Cool Tomohon. Profit margin untuk Freshmart Bahu Sebesar Rp. $12.250(43.75 \%)$ dari harga beli konsumen akhir. Nilai farmer's share terbesar diperoleh produsen 
dari hasil penjualan langsung kepada konsumen sebesar $100 \%$. Perbandingan margin pemasaran terbesar terjadi pada saluran pemasaran II yang dimulai dari produsen dengan Supermarket Freshmart Bahu yaitu nilai margin sebesar Rp. $13.000(46,42 \%)$ dari harga beli.

Tabel 5. Komponen Biaya Pengepakan Buah Stroberi

\begin{tabular}{lllll}
\hline $\begin{array}{l}\text { Biaya Yang Di } \\
\text { Keluarkan Petani }\end{array}$ & $\begin{array}{l}\text { Rata-Rata Biaya } \\
\text { (Rp /Kemasan) }\end{array}$ & $\begin{array}{l}\text { Biaya (Rp / } \\
\text { 100 Kemasan) }\end{array}$ & $\begin{array}{l}\text { Harga Jual } \\
\text { Petani }\end{array}$ & $\begin{array}{l}\text { Presentase Biaya } \\
\text { Terhadap Harga Jual }\end{array}$ \\
\hline Biaya Pengepakan & & & & \\
Petani-Konsumen & 250 & 25.000 & 13.500 & 1.85 \\
Petani-Cool Tomohon & 250 & 25.000 & 15.000 & 1.66 \\
Petani-Fresmart Bahu & 250 & 25.000 & 15.000 & 1.66 \\
\hline
\end{tabular}

Sumber: Data di olah dari data primer

\begin{tabular}{|c|c|c|c|c|}
\hline \multicolumn{5}{|c|}{ Tabel 6. Komponen Biava Pengangkutan Buah Stroberi } \\
\hline Biaya Yang Di & Biaya /100 & Rata-Rata Biaya & Harga Jual & Presentase Biaya \\
\hline Keluarkan Petani & Kemasan & Pengangkutan & Petani & Terhadap Harga Jual \\
\hline \multicolumn{5}{|l|}{ Biaya Pengangkutan } \\
\hline Petani-Konsumen & - & - & 13.500 & \\
\hline Petani-Cool Tomohon & 200 & 20.000 & 15.000 & 0.13 \\
\hline Petani Fresmart Bahu & 500 & 50.000 & 15.000 & 0.33 \\
\hline
\end{tabular}

Sumber : Data di olah dari data primer

Tabel 7. Rincian Margin dan Farmer's Share Pada Saluran I Antara Petani dan Konsumen.

\begin{tabular}{lll}
\hline Unsur Margin & Saluran I Harga Rp / Kemasan & Farmer's Share \\
\hline Harga Jual Petani & 13.500 & 100 \\
Biaya Pengepakan & 250 & 1.85 \\
Biaya Pengangkutan & - & - \\
Total Biaya & 250 & 1.85 \\
Margin & 0 & 0 \\
Profit Margin & 13250 & 98.14 \\
\hline
\end{tabular}

Sumber : Data di olah dari data primer

Tabel 8. Rincian Margin dan Farmer's Share Pada Saluran II Antara Petani Dengan Supermarket

\begin{tabular}{lllll}
\hline Unsur Margin & Cool & Freshmart & Farmer's Share Cool & Farmer's Share Freshmart \\
\hline Harga Jual Petani & 15000 & 15000 & 69.76 & 53.57 \\
Biaya Pengepakan & 250 & 250 & 1.16 & 0.89 \\
Biaya Pengangkutan & 200 & 500 & 0.93 & 1.78 \\
Harga Supermarket & 21500 & 28000 & 100 & 100 \\
Margin & 6500 & 13000 & 30.23 & 46.42 \\
Profi Margin & 6050 & 12250 & 28.13 & 43.75 \\
\hline
\end{tabular}

Sumber : Data di olah dari data primer 


\section{KESIMPULAN DAN SARAN}

\section{Kesimpulan}

Pemasaran buah stroberi dari Kelurahan Rurukan dan Rurukan Satu menggunakan dua saluran pemasaran yaitu: Petani ke Konsumen akhir, II A. Petani ke Supermarket Cool Tomohon, II B. Petani ke Supermarket Freshmart Bahu yang dilakukan oleh lima orang petani. Perbandingan nilai margin dari ke dua saluran pemasaran paling terbesar terdapat pada saluran pemasaran II yaitu antara Produsen dengan Freshmart Bahu yaitu sebesar Rp. 13.000 $(46,42 \%)$. Profit margin pada masing-masing saluran yaitu saluran pemasaran I adalah Rp. $13.250(98,14 \%)$, saluran pemasaran II yaitu pada Cool adalah Rp. 6050 (28,13\%), dan pada Freshmart adalah Rp. 12.250 (43,75\%). Nilai farmer's share, yang terbesar terdapat pada saluran pemasaran I. yaitu dari hasil penjualan langsung antara produsen dengan konsumen sebesar $100 \%$.

\section{Saran}

Pemerintah Daerah melalui instansi terkait supaya memberikan bantuan berupa modal dalam mengembangkan usahatani stroberi dan pemasaran stroberi serta mendukung organisasi-organisasi yang ada ditingkat petani, menfasilitasi sarana dan prasarana yang dibutuhkan petani mulai dari pengolahan sampai pada pemasaran produk. Pemerintah perlu mengadakan pelatihan tentang pengolahan stroberi agar dapat meningkatkan nilai tambah yang lebih baik bagi petani.

\section{DAFTAR PUSTAKA}

Anandita, 2004. Pemasaran Hasil Pertanian. Papirus. Surabaya.

Budiman, S. Dan D. Saraswati. 2008. Berkebun Stroberi Secara Komersial.Penebar Swadaya. Jakarta.
Gunawan, 2006. Usahatani Stroberi Lokal. Penerbit Armico. Bandung.

Hadian, D. 2005. Analisis Proses Keputusan Konsumen Berkunjung KeAgrowisata Stroberi di Desa Alamendah, Kecamatan Rancabali,Kabupaten Bandung, Jawa Barat.Skripsi. Departemen Ilmu-Ilmu Sosial Ekonomi. Fakultas Pertanian. Institut Pertanian Bogor.

Hanafie, 2010. Pengantar Ekonomi Pertanian. Penerbit Andi. Yogyakarta.

Kotler, Philip. 2002. Manajemen Pemasaran. Terjemahan. Jilid I edisi milenium. Prenhalindo. Jakarta

Kurniawati, S. R.2006. Analisis Sistem Pemasaran Buah Stroberi (Kasus di Desa Alamendah, Kecamatan Rancabali, Kabupaten Bandung, Propinsi JawaBarat).Skripsi.Program Sarjana Ekstensi Manajemen Agribisnis. Fakultas Pertanian.Institut Pertanian Bogor. Bogor.

Limbong, W. H dan P Sitorus. 1987. Pengantar Tataniaga Pertanian. Jurusan Ilmu-ilmu Sosial Ekonomi Pertanian, Bogor. Fakultas Pertanian IPB.

Radius DB. 2008. Kebun Stroberi 'Ngalingkung' Bandung. (diakses 20 mei 2010).

Seokartawi, 2002. Prinsip Dasar Manajemen Hasil-Hasil Pertanian (Teoridan Aplikasinya). PT RajaGrafindo Persada. Jakarta.

Sudiyono, 2002. Pemasaran Hasil Pertanian. Universitas Muhammadiyah.Malang. 